\section{Survey shows haphazard provision of UK stroke services}

\section{Mark Pownall, London}

A survey published this week by the Stroke Association, a UK charity, has found that 2000 to 3000 stroke patients may die every year because of "haphazard" provision of specialised stroke services.

The study was carried out by Dr Shah Ebrahim from the University of Bristol and Dr Judith Redfern from the Royal Free and University College Medical School, London, who surveyed doctors responsible for stroke care throughout the United Kingdom. Over 1700 completed questionnaires were returned by consultants responsible for stroke care, giving a response rate of $86.8 \%$, and by health authorities and health boards $(82 \%$ reponse rate). The researchers found that only about half of patients with stroke are admitted to organised stroke services. This was in spite of evidence gathered over the past 20 years that stroke units reduce mortality and disability by about $25 \%$ compared with management in acute general medical wards (BMJ 1997;314:1151-9).

The study found that up to 3000 stroke related deaths each year may be preventable, because only about half of stroke patients currently receive optimal specialist stroke care. The findings also implied that the admission to institutions of 2500-4000 patients each year because of post stroke disabilities could be prevented.

The researchers also found huge differences in the availability of organised stroke services (both acute and rehabilitation) across the United Kingdom. Those in Northern Ireland, Scotland, and Wales had best access to stroke care. English patients were worst off. Dr Ebrahim said: "If you live in Northern Ireland you have nearly twice the chance of getting specialist stroke care as you do in the south west of

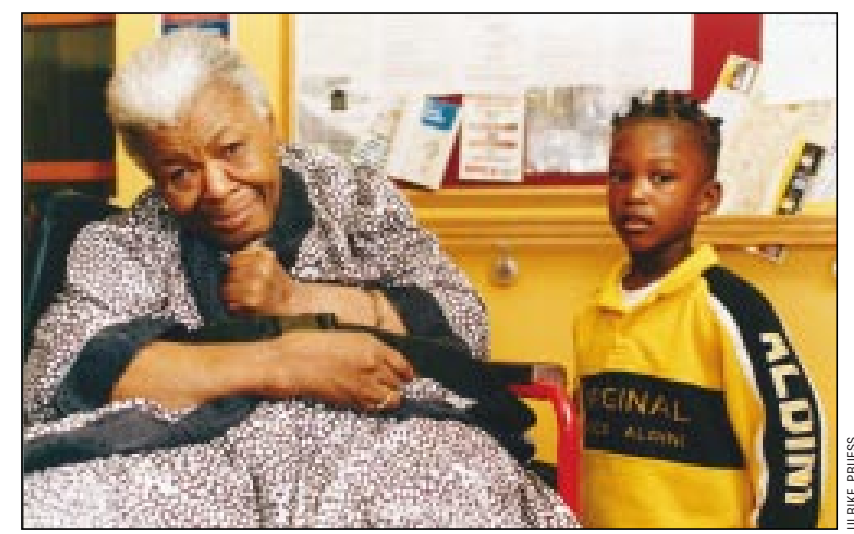

Access to specialist stroke services is haphazard

England, and this difference is not related to need. It is extremely disturbing."

The survey report warned: "There is wide and unacceptable variation around the country in the chances of being managed in an organised stroke service. This requires urgent action from health service commissioners." Currently, stroke services are commissioned "piecemeal," resulting in a lack of integration. In addition consultants work in an "information and policy vacuum," the report said

Dr Ebrahim said: "Some resource shifts have to be made to set up specialist stroke services, but that is an organisational challenge, and it requires strong leadership."

Stroke Care-A Matter of Chance. A National Survey of Stroke Service is available from The Stroke Association, Stroke House, Whitecross Street, London EC1Y 8JJ.

\section{No extra government funding for NHS staff over millennium period}

Caroline White, London

There will be no additional central funding or national guidelines for incentive payments for NHS staff over the millennium period, the government has decided. Employers will be expected to draw on the tradition of public service and commitment among staff as part of their effort to maintain services, the NHS circular issued last week advises.

The number of people who will attend non-ticketed events over the millennium period is unknown, and the NHS has not yet overcome its current shortage of nursing staff.

"It's a nice sentiment, but relying solely on goodwill is not enough," says Andrew Foster, the chairman of the Human Resources Committee of the NHS Confederation. Most human resources directors are aware that adequate millennium cover could be problematic, he says. "If there is no national funding for incentive payments, the costs will have to be borne locally by employers, and that means that funds will have to come out of somewhere else."

Some trusts have banded together to avoid competition for locum staff and ensure uniformity of local rates and cash incentives, said Mr Foster. Suggested one off payments were in the region of $£ 200$ (\$320) for New Year's Eve and $£ 100(\$ 160)$ for New Year's Day in London, and half as much elsewhere, or triple time. But no national rates have been agreed.

In February this year, the health services union, Unison, who had urged a national millennium pay plan, had requested incentive bonuses of $£ 500$ $(\$ 800)$ and $£ 250(\$ 400)$ for staff covering New Year's Eve and New Year's Day. Responding to government's decision, Bob Abberley, the head of health at Unison, said: "It's the worst of all worlds. We believe that trusts will compete to poach staff."
At a conference on prehospital immediate care for mass gatherings held in London last week Chris Gundry, emergency planning adviser for the south London and Surrey consortium of health authorities, said that the main area of risk for the millennium was not systems compliance but staffing levels. Although he believed that the NHS was well prepared to meet millennium demands, "[staffing] is the area which should be taxing minds," he said.

Dr Kenneth Hines, a general practitioner from south Woodford, east London, and an expert in medical services provision at mass gatherings, added that spontaneous events always caused problems, but that event organisers in London had failed to learn from previous mistakes. Closer collaboration between organisers and medical support services was needed, he suggested. "Promoters and events organisers tend to leave health people out of the planning loop, or only include us at the last minute." $\mathrm{He}$ called for the setting up of a database of the successes and failures of major incidents to inform future planning.

\section{Hospital meals should be part of clinical care}

Annabel Ferriman, BMJ

Forty per cent of adult hospital patients are undernourished, and many others become so during their time in hospital, says a new report on hospital nutrition, published by the Nuffield Trust. The effects of this are increased postoperative complications, lowered resistance to infection, and longer hospital stays.

The report recommends that food provision in hospitals should be considered as part of clinical care, rather than a "hotel" function. For many patients, it says, food is a "crucial aspect" of clinical treatment.

Nutritional care, it proposes, should be embedded in the new clinical governance framework.

Managing Nutrition in Hospital, by Alan Maryon Davis and Amanda Bristow, is published by the Nuffield Trust, 59 New Cavendish Street, London W1M 7RD. 